九州大学学術情報リポジトリ

Kyushu University Institutional Repository

\title{
Gene expression profiling of mammary glands of cathepsin E-deficient mice compared with wild- type Littermates
}

\section{Kawakubo, Tomoyo}

Department of Pharmacology, Graduate School of Dental Science, Kyushu University

Yasukochi, Atsushi

Department of Pharmacology, Graduate School of Dental Science, Kyushu University

Tsukuba, Takayuki

Department of Pharmacology, Graduate School of Dental Science, Kyushu University

Kadowaki, Tomoko

Department of Pharmacology, Graduate School of Dental Science, Kyushu University

他

http://hdl. handle. net/2324/4104131

出版情報: Biochimie. 90 (2)，pp.396-404，2008-02. Elsevier バージョン：

権利関係: Creative Commons Attribution-NonCommercial-NoDerivatives 4.0 International 
(Research Paper)

\title{
Gene expression profiling of mammary glands of cathepsin E-deficient mice compared with wild-type littermates
}

\author{
Tomoyo Kawakubo, Atsushi Yasukochi, Takayuki Tsukuba†, Tomoko Kadowaki, \\ Kenji Yamamoto*
}

Department of Pharmacology, Graduate School of Dental Science, Kyushu University, Fukuoka 812-8582, Japan

*Corresponding author: Tel.: +81-92-642-6337; fax: +81-92-642-6342.

E-mail address: kyama@dent.kyushu-u.ac.jp (K. Yamamoto)

$\dagger$ Present address: Department of Dental Pharmacology, Graduate School of Biomedical Sciences, Nagasaki University, Nagasaki 852-8588, Japan

\begin{abstract}
Cathepsin $\mathrm{E}$ is an endolysosomal aspartic proteinase predominantly expressed in cells of the immune system and has been implicated in various physiological and pathological processes. Because of physiological substrates of cathepsin $\mathrm{E}$ have not yet been identified, however, the physiological significance of this protein still remains speculative. To better understand the physiological significance of cathepsin $E$ in the mammary gland, we investigated the effect of the deficiency of this protein on the gene expression profile of the tissue. Here we used mammary glands derived from multiparous and non-pregnant 11-month-old syngenic wild-type $\left(\mathrm{CatE}^{+/+}\right)$and cathepsin E-deficient $\left(\mathrm{CatE}^{-/-}\right)$mice for extraction of total RNA from each tissue and subsequent mRNA amplification, DNA fragmentation, and hybridization with cDNA mixroarray
\end{abstract}


chips. A total of 654 genes were identified as overexpressed ( $>2$-fold) in $\mathrm{CatE}^{-/-}$ mammary glands compared with $\mathrm{CatE}^{+/+}$counterparts. These included genes related to signal transduction, immune responses, growth factor activity, and milk proteins, which occupied a large portion of the gene fragments identified as overexpressed. In contrast, a total of 665 known genes were identified as underexpressed in the mammary gland of $\mathrm{CatE}^{-/-}$mice compared with $\mathrm{CatE}^{+/+}$counterparts. These included genes related to cytoskeleton, cell differentiation, cell cycle arrest and apoptosis, which occupied the majority of the gene fragments identified as underexpressed. The results thus suggest that cathepsin $\mathrm{E}$ in mammary glands plays a crucial role in the regulation of proteins involved in signaling, development, differentiation and proliferation in the mammary gland.

Key words: aspartic proteinase, cathepsin E, mammary gland, gene expression profiling 


\section{Introduction}

Tissue remodeling is a key process involved normal development. The mammary gland undergoes extensive tissue remodeling during each lactation cycle. During pregnancy, the epithelial compartment of the gland is vastly expanded [1]. At the end of lactation the epithelial cells undergo apoptosis and adipocyte differentiation is induced [2]. Previous studies have demonstrated that ductal and alveolar growth during puberty and pregnancy, and the involution process are mediated by the action of proteases, including, matrix metalloproteinases (MMPs), plasminogen, membrane-peptidases, and cathepsin $\mathrm{D}$, and the corresponding genes are activated during these periods $[1,3,4]$. MMPs are expressed in several cell types of the mammary gland, including stromal fibroblasts (e.g., MMP3, MMP2), epithelial cells (e.g. MMP7, MMP9), adipocytes (e.g., MMP2) and lymphoid cells (e.g. MMP9) [5, 6]. Several knockout mouse strains, including MMP2-, MMP3- or plasminogen-deficient mice, have displayed alterations to mammary gland structure and impairment of lactation $[5,6]$ and provided important insight into their functions in the mammary gland.

Cathepsin E is an intracellular aspartic proteinase of the pepsin superfamily, which is expressed predominantly in cells of the immune system [7-10] and highly secreted by activated phagocytes [11]. Like other pepsin family members, cathepsin E requires an acidic environment for optimal activity and is believed to be involved in unspecific bulk proteolysis in endolysosomal compartments, but there is growing evidence that this enzyme has specific, non-redundant functions $[12,13]$. On the other hand, cathepsin $\mathrm{E}$ 
possesses several unique properties not shown by other pepsin family members. Unlike other intracellular aspartic proteinases, cathepsin E forms a homodimer that is not necessarily required for expressing activity, correct intracellular localization, and carbohydrate modification, but is essential to structural stabilization of the molecule [14, 15]. Besides their structural and immunological distinction [16-22], cathepsin $\mathrm{E}$ is different from other pepsin family members in tissue distribution and intracellular localization $[7,8,10,23]$. Differing from the definite localization of the analogous lysosomal aspartic proteinase cathepsin $\mathrm{D}$, the intracellular localization of cathepsin $\mathrm{E}$ appears to vary with cell types $[8,10,23]$. In antigen presenting cells such as dendritic cells, microglia, and macrophages, cathepsin $\mathrm{E}$ is mainly found in endosomal structures mainly as a mature enzyme which is N-glycosylated mostly with complex-type oligosaccharides [8]. In some types of cells, including erythrocytes, renal proximal tubule cells, and osteoclasts, cathepsin $\mathrm{E}$ is exclusively confined to the plasma membrane $[23,24]$ mainly as a proenzyme having complex-type oligosaccharides. In a variety of other cell types, cathepsin $\mathrm{E}$ is also detected in the endoplasmic reticulumn and Golgi complex $[10,23,25]$. Cathepsin $\mathrm{E}$ has been implicated in various physiological and pathological processes [see for review refs. 26, 27], the precise role of this protein remains largely unknown, because the physiological substrates of this protein have not yet been identified. Recent genetic approaches using mice lacking cathepsin $\mathrm{E}$ have provided important insight into their biological functions [28-30]. Cathepsin E-deficient $\left(\mathrm{CatE}^{-/-}\right)$mice were shown to spontaneously develop atopic 
dermatitis-like skin lesions when reared under conventional conditions [28] and exhibit the increased susceptibility to bacterial infection accompanied by a marked decrease in killing of intracellular bacteria by macrophages [29]. Subsequent analysis of macrophages derived from $\mathrm{CatE}^{-/-}$mice revealed that the deficiency of this protein induced a novel form of lysosomal storage disorder manifesting the accumulation of major lysosomal membrane sialoglucoproteins such as LAMP-1 and LAMP-2 and the elevation of lysosomal $\mathrm{pH}[30]$. Based on these observations, it has strongly been suggested that cathepsin E contributes to the maintenance of homeostasis by participating in host defense mechanisms.

. The aim of the present study was to gain further insight into the mechanisms underlying cathepsin E functions in mammary glands in vivo, because this protein also exists in the reproductive system including mammary glands, besides the immune system. To better understand the physiological significance of cathepsin $\mathrm{E}$ in mouse mammary gland, the strategy was to take advantage of $\mathrm{CatE}^{-/-}$mice. We thus performed global gene expression profiling of mammary glands and conducted a screen that select specifically for genes that were significantly altered by cathepsin E deficiency.

\section{Materials and Methods}

\section{Animals}

Wild-type and $\mathrm{CatE}^{-/-}$mice with C57BL/6 genetic background were housed as described previously [28]. All animals were maintained under specific pathogen-free conditions at 
Kyushu University Station of Collaborative Research animal facilities according to the guidelines of the Japanese Pharmacological Society. All animal experiments were approved with the Animal Research Committee of Graduate School of Dental Science, Kyushu University.

\section{Real time RT-PCR}

Total RNA was isolated with the RNeasy Mini Kit (Qiagen, Valencia, CA) according to the manufacturer's instructions. The yield and quality of RNA was evaluated by measuring its absorbance at A260/A280 and gel electrophoresis. cDNA synthesis was performed using an Ready-to-Go RT-PCR Beads (Amersham Biosciences Co., NJ, USA). A total of $1 \mu \mathrm{g}$ of each sample was incubated in a $50 \mu$ reaction mixture containing first-strand primers, forward and reverse primers $(20$ pmol $)$, and RNase/DNase free water. RT was performed using a thermal program of $45{ }^{\circ} \mathrm{C}$ for 15 min, and $95^{\circ} \mathrm{C}$ for $5 \mathrm{~min}$. The specificity of each primer set was first tested by RT-PCR, followed by melting curve analysis using DyNAmo ${ }^{\mathrm{TM}}$ HS SYBR ${ }^{\circledR}$ Green qPCR Kit (Finnzymes, Espoo, Finland) with an Rotor-Gene ${ }^{\mathrm{TM}} 3000$ (NIPPN TechnoCluster, Inc., Tokyo, Japan) and gel electrophoresis of the PCR products. Gene-specific forward and reverse cathepsin E primers were 5'-GTGCCCCTCAGAAGACATCA-3' and 5'-GTATCCCAGACCCAGAATCC-3', respectively. G3PDH expression was monitored as an endogenous control, during each PCR reaction. The forward and reverse primers for G3PDH were 5'-TCCACCACCCTGTTGCTGTA-3' and 5'-ACCACAGTCCATGCCATCAC-3', respectively. Each PCR reaction was carried 
out in triplicate in a total volume of $20 \mu \mathrm{l}$, containing master mix which contains hot start version of a modified Tbr DNA polymerase, SYBR Green I, optimized PCR buffer, $5 \mathrm{mM} \mathrm{MgCl}_{2}$, dNTP mix including dUTP, forward primer, reverse primer, water, and cDNA. Thermocycling conditions were as follows: $95{ }^{\circ} \mathrm{C}$ for $15 \mathrm{~min}$, followed by 45 cycles at $94{ }^{\circ} \mathrm{C}$ for $10 \mathrm{~s}, 57^{\circ} \mathrm{C}$ for $30 \mathrm{~s}$, and $72{ }^{\circ} \mathrm{C}$ for $30 \mathrm{~s}$ for cathepsin $\mathrm{E}, 95^{\circ} \mathrm{C}$ for 15 min, followed by 35 cycles at $94{ }^{\circ} \mathrm{C}$ for $10 \mathrm{~s}, 60{ }^{\circ} \mathrm{C}$ for $20 \mathrm{~s}$, and $72{ }^{\circ} \mathrm{C}$ for $30 \mathrm{~s}$ for G3PDH, with fluorescent readings at the end of each cycle. Total RNA from wild-type mouse stomach was used as a positive control.

\section{Immunoblot analysis}

SDS-PAGE and immunoblot analysis were performed as described previously [31]. After transfer of proteins fractionated by SDS-PAGE to a nitrocellulose membrane and blocking with 5\% nonfat dried milk in Tris-buffered saline, the membrane was incubated overnight at $4{ }^{\circ} \mathrm{C}$ with primary antibody to cathepsin $\mathrm{E}$ (diluted $1 / 4000$ ). After washing, the membrane was incubated overnight at $4{ }^{\circ} \mathrm{C}$ with horseradish peroxidase-conjugated secondary antibody to rabbit immunoglobulin G (diluted 1/2000; Biosource International, Camarillo, CA). The membrane was washed several times and immune complexes were detected with chemiluminescence reagents (GE Healthcare UK Ltd., Buckinghamshire, England). Densitometry was performed with a LAS1000 analyzer (FUJIFILM Corp., Tokyo, Japan).

\section{Acid treatment}

Fifty $\mu \mathrm{g}$ of the tissue extract from wild-type mouse mammary gland was incubated at 


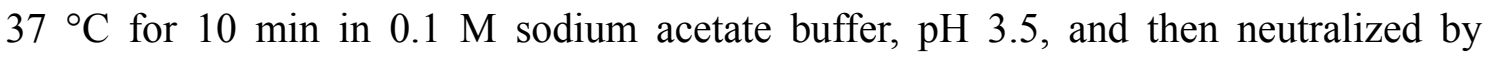
addition of $0.1 \mathrm{M}$ Tris- $\mathrm{HCl}$ buffer, $\mathrm{pH}$ 9.0. Then the samples were analyzed by SDS-PAGE under reducing conditions and immunoblotting.

\section{Whole mount}

Whole mounts were prepared following protocols described by the Laboratory of Genetics and Physiology at the National Institute of Diabetes, Digestive and Kidney Diseases within the National Institutes of Health (http://mammary.nih.gov), and Thompson et al. [32]. The mammary glands from wild-type and $\mathrm{CatE}^{-/-}$mice were removed and spread on a glass slide, fixed overnight in $10 \%$ phosphate-buffered formalin, dehydrated in 70, 95, and 100\% alcohols, cleared in toluene, rehydrated and stained with Carmine Alum (Sigma-Aldrich Japan) overnight. After staining, the whole mounts were dehydrated as described above, cleared in xylene for $30 \mathrm{~min}$, and mounted. The whole mounts were analyzed under a stereomicroscope for microscopic lesions.

\section{Microarray studies}

Mammary glands from multiparous and non-pregnant wild-type and CatE ${ }^{-/-}$mice at 11 months of age were excised, and immediately immersed in RNAlater RNA Stabilization Reagent (QIAGEN Sciences, Inc., Chatsworth, MD). Total RNA was isolated from each of the mammary glands using an RNA purification kit (RNeasy Mini Kit; QIAGEN Sciences, Inc., Chatsworth, MD). The total RNA was checked its qualities by the Agilent 2100 BioAnalyzer (Agilent Technologies, Santa Clara, CA) and a spectrometer (NanoDrop Technologies, Inc, Wilmington, DE), followed by mRNA 
amplification using a T7 global amplification method (Two-Cycle Target Labeling kit; Affymetrix), DNA fragmentation, biotinylation, and hybridization with cDNA microarray chips, GeneChip ${ }^{\circledR}$ Mouse Genome 4302.0 Array (Affymetrix, Inc., CA) containing probes representing more than 45000 mouse genes and expressed sequence tags. The scanned arrays passed the quality control standards such as visual inspection and eukaryotic control performance standards suggested by the manufacturer (Affymetrix). Gene expression data were analyzed using the software Signet Viewer (BIO MATRIX RESEARCH, Inc., Chiba, Japan; the authorized provider by Affymetrix). For genotypic comparisons (CatE $E^{-/-}$vs. wild-type), we initially excluded the data included more over 3 merginal or absent signals on the hybridization pattern with Perfect match (PM) and Mismatch (MM) probes, and the probe sets identified from the analysis at a false discovery rate (FDR) cut-off of 0.05 are listed in.

\section{Results}

\section{Characterization of cathepsin $\mathrm{E}$ in mouse mammary gland}

Previous studies in our laboratory have shown that cathepsins E and D are detected differentially in various exocrine glands including submandibular gland and lachrymal gland [7], we thus sought the expression levels of cathepsin E in mouse mammary gland using a quantitative RT-PCR technique. The mammary glands as well as brain, pancreas, spleen and stomach derived from multiparous and non-pregnant C57BL/6 mice at 11 months of age were isolated after perfusion with saline. Total RNA was extracted and 
cDNA synthesized. Real-time PCR amplification and subsequent quantitation revealed that the level of cathepsin E mRNA in the mammary gland was higher than that in brain and pancreas but lower than that in spleen and stomach (Fig. 1A). Western blot analysis of the cell lysate of mammary glands under reducing conditions revealed a major $42-\mathrm{kDa}$ band and a minor $46-\mathrm{kDa}$ band corresponding to the monomeric mature and precursor forms of cathepsin E, respectively (Fig. 1B), indicating that cathepsin E in the mammary gland is largely expressed as the mature enzyme. This was further confirmed by acid treatment of the lysate at $\mathrm{pH} 3.5$ and $37^{\circ}$ for $10 \mathrm{~min}$, because the proenzyme is rapidly converted to the mature form at $\mathrm{pH}$ values below $\mathrm{pH} 4$ [33]. The electrophoretic mobility of the $42-\mathrm{kDa}$ form of cathepsin $\mathrm{E}$ was not changed by acid treatment, indicating that this is the processed mature enzyme.

\section{Gene expression differences in mammary glands between $\mathrm{CatE}^{-/-}$and wild-type} mice

To determine the common molecular alterations induced by cathepsin E deficiency in the mammary gland, we performed global gene expression profiling of the mammary gland from wild-type and $\mathrm{CatE}^{-/-}$mice at 11 months of age. Allowing for a false discovery rate of 0.05 , of the 45101 genes detected on the array, a total 654 gene fragments were identified as overexpressed (>2-fold) in the mammary gland of CatE $E^{-/}$ mice compared with the normal mammary gland of wild-type littermates (Table 1), whereas a total 665 gene fragments were identified as underexpressed in the mammary gland of $\mathrm{CatE}^{-/-}$mice compared with the normal mammary gland of wild-type 
littermates (Table 2). Genes related to signal transduction and immune response, including aurora kinase $\mathrm{C}$, chemokine ligands, defensin beta, and tumor necrosis factor family members, and genes related to growth factor activity such as nodal and insulin-like growth factor binding protein (IGFBP) 2 occupied a large portion of the 654 gene fragments identified as overexpressed in the mammary gland of $\mathrm{CatE}^{-/-}$mice (Table 3). In addition, genes associated with milk proteins, including whey acidic protein (WAP) and lactalbumin, comprised a significant part of the overexpressed genes by cathepsin E deficiency (Table 1). On the other hand, genes related to cytoskeleton proteins including myosin, toroponin, actinin, troponin, toropomyosin, titin, and actin occupied the majority of the 665 gene fragments identified as underexpressed in the mammary gland of $\mathrm{CatE}^{-/-}$mice (Table 4). Furthermore, genes related to cell differentiation, cell cycle arrest and apoptosis comprised a significant part of the underexpressed genes by cathepsin E deficiency.

\section{Whole mount of mammary gland}

To gain more information about the influence of cathepsin E deficiency on phenotypic differences between wild type and $\mathrm{CatE}^{-/-}$mice, the mammary gland whole-mount preparations were carried out. The morphology of the mammary tree of $\mathrm{CatE}^{-/-}$mice appeared to be grossly abnormal compared with that of the wild-type littermates (Fig. 2). The mammary tree of $\mathrm{CatE}^{-/}$mice showed more enlarged ducts having multiple hyperplastic alveolar nodules compared with that of wild-type animals. Furthermore, the mammary gland of $\mathrm{CatE}^{-/-}$mice had supernumerary budding along the primary ducts 
compared with the wild-type one.

\section{Discussion}

Cathepsin $\mathrm{E}$ is one of the most enigmatic aspartic proteinases in the pepsin family members. This enzyme can be detected in both intracellular and extracellular spaces under various physiological and pathological conditions. Its expression at both mRNA and protein levels is significantly increased in antigen presenting cells upon stimulation with interferon- $\gamma$ and lipopolysaccharide $[10,11]$ and inversely decreased in these cells by treatment with IL-10 [11]. Cathepsin E expression is also increased in vivo in both glial cells and neurons in the vulnerable regions of rat brain to transient forebrain ischemia [34] and in the senescent rat brain [35], and at the advancing margins of gastric carcinomas and in inflammatory cells within and nearby carcinomas [36]. Its cleavage specificity toward certain peptide substrates also changes with $\mathrm{pH}$ [37]. Therefore, these unique properties and flexibilities may confer pleiotropic nature and manifold functions on cathepsin E. Furthermore, recent gene or protein expression profiling of cartain cancers suggests the clinical utility of cathepsin $\mathrm{E}$ as a potential cancer biomarker [38-42], although the views on its role in carcinogenesis are not necessarily consistent among the literature.

The present study was undertaken to gain further insight into the physiological significance of cathepsin $\mathrm{E}$ in the mammary gland and the identification of candidate proteins regulated by this protein. We first analyzed the gene expression profiles of 
$\mathrm{CatE}^{-/-}$mammary gland and compared them with those of normal mammary gland of wild-type mice. Strikingly, a total of 654 known genes were increased ( $>2$-fold) in $\mathrm{CatE}^{-/-}$mammary glands compared with $\mathrm{CatE}^{+/+}$counterparts. These included genes related to signal transduction and immune responses, growth factor activity, and milk proteins, which comprised a large portion of the gene fragments identified as overexpressed. Like aurora kinase $\mathrm{A}$ and $\mathrm{B}$, aurora kinase $\mathrm{C}$ identified as an overexpressed signal transduction-related gene in $\mathrm{CatE}^{-/-}$mammary glands is involved in various biological processes, including cytokinesis and dysregulated chromosome segregation [43]. Although the precise role and regulation of aurora kinase $\mathrm{C}$ is largely unknown, the expression level of this kinase is increased in several human cancer cell types [44], and inhibitors of these kinases are expected to be novel antioncogenic agents. Chemokines such as CXCL12 were also identified as overexpressed by cathepsin E deficiency. These chemokines are also known to up-regulate in tumor myoepithelial cells and bind to their receptors on epithelial cells and thereby enhance the proliferation, migration, and invasion of these cells [45], implying that the increased expression of these chemokines may be associated with tumorigenesis of the mammary gland. Up-regulation of the growth factor activity-related genes such as nodal and IGFBP2 are known to be associated with cell proliferation [46]. IGFBP2 has shown to play a role in the normal development of mammary gland tissue or the mammary gland tumor etiology [47]. The mitogenic signals of IGFBP2 through autocrine/paracrine regulatory mechanisms are believed to be responsible for the growth of mammary gland 
carcinomas and to serve as an indicator of malignancy [46]. Thus, the present results suggest that up-regulation of the signal transduction/immune response-related genes and the growth factor activity-related genes by cathepsin E deficiency may be associated with the induction of hyperplastic or carcinogenic alterations in mouse mammary gland.

In contrast, a total of 665 known genes were decreased in the mammary gland of $\mathrm{CatE}^{-/-}$mice compared with $\mathrm{CatE}^{+/+}$counterparts. Of these genes identified as underexpressed, 31 genes were related to cytoskeleton/smooth muscle-related molecules $(>2$-fold decrease). It is well known that the most important portion of the mammary gland development occurs postnatally, with distinct periods of intensive morphogenesis taking place between birth and puberty and during pregnancy and lactation. A mammary epithelium bilayer is organized by luminal secretory and basal myoepithelial cells. During postnatal development, mammary myoepithelial cells progressively acquire a differentiated phenotype as revealed by the expression of various smooth muscle-related markers $[48,49]$. Therefore, mammary gland differentiation is more likely to be closely related to gene expression of cytoskeleton/smooth muscle-associated molecules. Myogenic factor 6 identified as underexpressed in $\mathrm{CatE}^{-/}$mammary gland is known to be specifically involved in development of muscle [50]. Interestingly, morphological analysis revealed that the $\mathrm{CatE}^{-/}$mammary gland appears to lead to aberrant myoepithelial cell differentiation and abnormal mammary gland development. In addition, there were genes related cell cycle arrest and anti-apoptosis identified as underexpressed by cathepsin E deficiency. Given that the growth and development of 
mammary gland are regulated by a balance between positive and negative factors of cell proliferation, these genes identified as overexpressed by cathepsin E deficiency are likely to contribute to the growth and development of this tissue.

Importantly, we also provide the first evidence that cathepsin E deficiency may disrupt the epithelial-mesenchymal transition in the mammary gland. In physiological conditions, the mammary gland is hormonally regulated through transition between glanular epithelium and adipose tissue. In virgin female mice, most of the resting gland consists of adipocytes, but during pregnancy and lactation $\sim 90 \%$ of the organ is occupied with secretory epithelial cells. After lactation, rapid adipogenesis is induced. This epithelial-mesenchymal transition is regulated a proper balance between differentiation and proliferation-related gene expression. In this study, the genes related to milk proteins such as WAP and lactalbumin alpha were identified as overexpressed by cathepsin E deficiency. WAP is a principal whey protein found in rodent milk that contains a cysteine-rich motif identified in some protease inhibitors and proteins involved in tissue modeling. The expression of the Wap gene is known to be increased more than 1,000-fold around mid-pregnancy [51]. Although WAP is not required for alveolar specification and functional differentiation, it is used as a marker for advanced differentiation of mammary epithelial cells. Furthermore, WAP plays a negative regulatory role in the cell cycle progression of mammary epithelial cells through an autocrine or paracrine mechanism [51]. Therefore, up-regulation of the Wap gene by cathepsin E deficiency is more likely to accelerate cell differentiation proliferation in 
the mammary gland. Our results thus suggest that cathepsin E may play a crucial role in regulation of the epithelial-mesenchymal transition.

\section{Conclusion}

To better understand the physiological significance of cathepsin $\mathrm{E}$ in mouse mammary

gland, we performed gene expression profiling of the tissues of syngenic wild-type and $\mathrm{CatE}^{-/-}$mice. Several genes involved in signal transduction/immune responses and growth were overexpressed, whereas many genes involved in cytoskeleton, cell differentiation, and cell cycle arrest/anti-apoptosis were underexpressed. Therefore, gene expression profiling revealed that cathepsin E might be involved in the regulation of signaling, development, and cell proliferation and differentiation in the mammary gland.

\section{References}

[1] C. Benaud, R. B. Dickson, E. W. Thompson, Roles of the matrix metalloproteinases in mammary gland development and cancer, Breast Cancer Res. Treat. 50 (1998) 97-116.

[2] J. Lilla, D. Stickens, Z. Werb, Metalloproteases and Adipogenesis: A Weighty Subject, Am. J. Pathol. 160 (2002) 1551-1554.

[3] C.M. Alexander, S. Selvarajan, J. Mudgett, Z. Werb, Stromelysin-1 Regulates Adipogenesis during Mammary Gland Involution, J. Cell. Biol. 152 (2001) 693-703.

[4] P.S. Rudland, R. Barraclough, D.G. Fernig, J.A. Smith, Growth and differentiation of the normal mammary gland and its tumors, Biochem. Soc. Symp. 63 (1998) 1-20. 
[5] L.R. Lund, J. Rømer, N. Thomasset, H. Solberg, C. Pyke, M.J. Bissell, K. Danø, Z. Werb, Two distinct phases of apoptosis in mammary gland involution: proteinase-independent and -dependent pathways, Development 122 (1996) $181-193$

[6] B.S. Wiseman, M.D. Sternlicht, L.R. Lund, C.M. Alexander, J. Mott, M.J. Bissell, P. Soloway, S. Itohara, Z. Werb, Site-Specific inductive and inhibitory activities of MMP-2 and MMP-3 orchestrate mammary gland branching morphogenesis, J. Cell Biol. 162 (2003) 1123-1133.

[7] H. Sakai, T. Saku, Y. Kato, K. Yamamoto, Quantitation and immunohistochemical localization of cathepsins E and D in rat tissues and blood cells. Biochim. Biophys. Acta 991(1989) 367-375.

[8] D.F. Sastradipura, H. Nakanishi, T. Tsukuba, K. Nishishita, H. Sakai, Y. Kato, T. Gotow, Y. Uchiyama, K. Yamamoto, Identification of cellular compartments involved in processing of cathepsin $\mathrm{E}$ in primary cultures of rat micriglia. J. Neurochem. 70 (1998) 2045-2056.

[9] P.J. Tatnell, S.D. Fowler, D. Bur, W.E. Lees, and J. Kay, Cathepsin E: the best laid plans of mice and men. Adv. Exp. Med. Biol. 436 (1998) 147-152.

[10] T. Nishioku, K. Hashimoto, K. Yamashita, S.Y. Liou, Y. Kagamiishi, H. Maegawa, N. Katsube, C. Peters, K. von Figura, P. Saftig, N. Katsunuma, K. Yamamoto, H. Nakanishi, Involvement of cathepsin $\mathrm{E}$ in exogenous antigen processing in primary cultured murine microglia, J. Biol. Chem. 277 (2002) 4816-4822.

[11] M. Yanagawa, T. Tsukuba, K. Okamoto, R. Takii, Y. Terada, T. Kadowaki, K. 
Yamamoto, Up-regulation, enhanced maturation, and secretion of cathepsin E in mouse macrophages treated with interferon- $\gamma$ or lipopolysaccharide, J. Oral Biosci. 48 (2006) 218-225.

[12] T. Kageyama, Rabbit procathepsin E and cathepsin E. Nucleotide sequence of cDNA, hydrolytic specificity for biologically active peptides and gene expression during development. Eur. J. Biochem. 216 (1993) 717-728.

[13] T. Kageyama, M. Ichinose, S. Yonezawa, Processing of the precursors to neurotensin and other bioactive peptides by cathepsin E. J. Biol. Chem. 270 (1995) 19135-19140.

[14] S.D. Fowler, J. Kay, B.M. Dunn, P.T. Tatnell, Monemeric human cathepsin E. FEBSLett. 366 (1995) 72-74.

[15] T. Tsukuba, H. Sakai, M. Yamada, H. Maeda, H. Hori, T. Azuma, A. Akamine, K. Yamamoto, Biochemical properties of the monomeric mutant of human cathepsin E expressed in Chinese hamster ovary cells: comparison with dimeric forms of the natural and recombinant cathepsin E. J. Biochem. 119 (1996) 126-134.

[16] T. Azuma, G. Pals, T.K. Mohandas, J.M. Couvreur, R.T. Taggart, Human gastric cathepsin E. Predicted sequence, localization to chromosome 1, and sequence homology with other aspartic proteinases. J. Biol. Chem. 264 (1989) 16748-16753.

[17] T. Kageyama, M. Ichinose, S. Tsukada, K. Miki, K. Kurokawa, O. Koiwai, M. Tanji, E. Yakabe, B.P. Athauda, K. Takahashi, Gastric procathepsin E and progastricsin from guinea pig. Purification, molecular cloning of cDNAs, and 
characterization of enzymatic properties, with special reference to procathepsin E. J. Biol. Chem. 267 (1992) 16450-16459.

[18] K. Okamoto, H. Yu, Y. Misumi, Y. Ikehara, K. Yamamoto, Isolation and sequencing of two cDNA clones encoding rat spleen cathepsin $\mathrm{E}$ and analysis of the activation of purified procathepsin E. Arch. Biochem. Biophys. 322 (1995) 103-111.

[19] P.J. Tatnell, W.E. Lees, J. Kay, Cloning, expression and characterization of murine procathepsin E. FEBS Lett. 408 (1997) 62-66.

[20] N. Ostermann, B. Gerhartz, S. Worpenberg, J. Trappe, J. Eder, Cryasatl structure of an activation intermediate of cathepsin E. J. Mol. Biol. 342 (2004) 889-899.

[21] K. Yamamoto, O. Kamata, N. Katsuda, K. Kato. Immunochemical difference between cathepsin D and cathepsin E-like enx¥zyme from rat spleen. J. Biochem. 87 (1980) 511-516.

[22] K. Yamamoto, E. Ueno, H. Uemura, Y. Kato, Biochemical and immunochemical similarity between erythrocyte membrane aspartic proteinase and cathepsin E. Biochem. Biophys. Res. Commun. 148 (1987) 267-272.

[23] T. Saku, H. Sakai, Y. Shibata, Y. Kato, K. Yamamoto, An immunocytochemical study on distinct intracellular localization of cathepsin E and cathepsin D in human gastric cells and various rat cells. J. Biochem. 110 (1991) 956-964.

[24] Y. Yoshimine, T. Tsukuba, R. Isobe, M. Sumi, A. Akamine, K. Maeda, K. Yamamoto, Specific immunocytochemical localization of cathepsin E at the ruffled border membrane of active osteoclasts. Cell Tissue Res. 281 (1995) 85-91. 
[25] H. Sakai, Y. Kato, K. Yamamoto. Synthesis and intracellular distribution of cathepsins E and D in differentiating murine Friend erythroleukemia cells. Arch. Biochem. Biophys. 292 (1992) 412-417.

[26] K. Yamamoto, Cathepsin E and cathepsin D. in: V. Turk (ed.), Proteases: New Perspectives, Birkhäuser Verlag, Basel, Switzerland.

[27] T. Tsukuba, K. Okamoto, Y. Yasuda, W. Morikawa, H. Nakanishi, K. Yamamoto, New functional aspects of cathepsin D and cathepsin E. Mol. Cells 10 (2000) 601-611.

[28] T. Tsukuba, K. Okamoto, Y. Okamoto, M. Yanagawa, K. Kohmura, Y. Yasuda, H. Uchi, T. Nakahara, M. Furue, K. Nakayama, T. Kadowaki, K. Yamamoto, K.I. Nakayama, Association of cathepsin E deficiency with development of atopic dermatitis. J. Biochem. 134 (2003) 893-902.

[29] T. Tsukuba, S. Yamamoto, M. Yanagawa, K. Okamoto, Y. Okamoto, K.I. Nakayama, T. Kadowaki, K. Yamamoto, Cathepsin E-deficient mice show increased susceptibility to bacterial infection associated with the decreased expression of multiple cell surface Toll-like receptors, J. Biochem. 140 (2006) 57-66.

[30] M. Yanagawa, T. Tsukuba, T. Nishioku, Y. Okamoto, K. Okamoto, R. Takii, Y. Terada, Y. K.I. Nakayama, T. Kadowaki, K. Yamamoto, Cathepsin E deficiency induces a novel form of lysosomal storage disorder showing the accumulation of lysosomal membrane sialoglycoproteins and the elevation of lysosomal $\mathrm{pH}$ in macrophages, J. Biol. Chem. 282 (2007) 1851-1862. 
[31] K. Yamamoto, M. Ezaki, H. Yamamoto, M. Tatsumi, Y. Kato, Human erythrocyte membrane acid proteinase (EMAP): sidedness and relation to cathepsin D. J. Biochem. 97 (1986) 821-830.

[32] H. Thompson, Z. Zhu, S. Banni, K. Darcy, T. Loftus, C, Ip, Morphological and biochemical status of the mammary gland as influenced by conjugated linoleic acid: implication for a reduction in mammary cancer risk, Cancer Res. 57 (1997) $5067-5072$.

[33] M. Takeda-Ezaki, K. Yamamoto, Isolation and biochemical characterization of procathepsin E from human erythrocyte membranes, Biochim Biophys Acta. 304 (1993) 352-358.

[34] H. Nakanishi, T. Tsukuba, T. Kondou, T. Tanaka, K. Yamamoto, Transient forebrain ischemia induces increased expression and specific localization of cathepsins E and D in rat hippocampus and neostriatum, Exp. Neurol. 121 (1993) 215-223.

[35] H. Nakanishi, K. Tominaga, T. Amano, I. Hirotsu, T. Inoue, K. Yamamoto, Age-related changes in activities and localizations of cathepsins D, E, B, and L in the rat brain tissues, Exp. Neurol. 126 (1994) 119-128.

[36] K. Matsuo, I. Kobayashi, T. Tsukuba, T. Kiyoshima, Y. Ishibashi, A. Miyoshi, K. Yamamoto, H. Sakai, Immunohistochemical localization of cathepsin D and E in human gastric cancer: a possible correlation with local invasive and metastatic activities of carcinoma cells, Hum. Pathol. 27 (1996) 184-190.

[37] S.B. Athauda, K. Takahashi, Distinct cleavage specificity of human cathepsin E at neutral pH with special preference for Arg-Arg bonds, Protein Pept. Lett. 9 (2002) $15-22$ 
[38] K. Uno, T. Azuma, M. Nakajima, K. Yasuda, T. Hayakumo, H. Mukai, T. Sakai, K. Kawai, Clinical significance of cathepsin $\mathrm{E}$ in pancreatic juice in the diagnosis of pancreatic ductal adenocarcinoma, J. Gastroenterol. Hepatol. 15 (2000) 1333-1338.

[39] R. Ullmann, P. Morbini, I. Halbwedi, M. Bongiovanni, M. Gogg-Kammerer, M. Papotti, S. Gabor, H. Renner, H.H. Popper, Protein expression profiles in adenocarcinomas of lung generated using tissue microarrays, J. Pathol. 203 (2004) 798-807.

[40] L. Busquets, H. Guillen, M.E. DeFord, M.A. Suckow, R.M. Navari, F.J. Castellino, M. Prorok, Cathepsin E is a specific marker of dysplasia in $\mathrm{APC}^{\mathrm{min} /+}$ mouse intestine, Tumor Biol. 27 (2006) 36-42.

[41] E. Blaveri, J.P. Simko, J.E. Korkola, J.L. Brewer, F. Baehner, K. Mehta, S. DeVries, T. Koppie, S. Pejavar, P. Carroll, F.M. Waldman, Bladder cancer outcome and subtype classification by gene expression, Clin. Cancer Res. 11 (2005) 4044-4055.

[42] P.J. Wild, A. Herr, C. Wissmann, R. Stoehr, A. Rosenthal, D. Zaak, R. Simon, R. Knuechel, C. Pilarsky, A. Hartmann, Gene expression profiling of progressive papillary noninvasive carcinomas of the urinary bladder, Clin. Cancer Res. 11 (2005) 4415-4429.

[43] P. Meraldi, R. Honda, E.A. Nigg, Aurora kinases link chromosome segregation and cell division to cancer susceptibility, Curr. Opin. Genet. Dev. 14 (2004) 29-36.

[44] J.J. Li, S.A. Li, Mitotic kinases: the key to duplication, segregation, and cytokinesis errors, chromosomal instability, and oncogenesis, Pharmacol Ther. 111 (2006) 
974-984.

[45] M. Allinen, R. Beroukhim, L. Cai, C. Brennan, J. Lahti-Domenici, H. Huang, D. Porter, M. Hu, L. Chin, A. Richardson, S. Schnitt, W.R. Sellers, K. Polyak, Molecular characterization of the tumor microenvironment in breast cancer, Cancer Cell 6 (2004) 17-32.

[46] L.T. Busund, E. Richardsen, R. Busund, T. Ukkonen, T. Bjørnsen, C. Busch, H. Stalsberg, Significant expression of IGFBP2 in breast cancer compared with benign lesions, J. Clin. Pathol. 58 (2005) 361-366.

[47] M.A. Allar, T.L. Wood, Expression of the Insulin-Like Growth Factor Binding Proteins during Postnatal Development of the Murine Mammary Gland, Endocrinology 145 (2004) 2467-2477.

[48] F. Jolicoeur, Intrauterine breast development and the mammary myoepithelial lineage, J. Mammary Gland Biol. Neoplasia 10 (2005) 199-210.

[49] M.A. Deugnier, E.P. Moisevera, J.P. Thiery, M. Glukhova, Myoepithelial cell differentiation in the developing mammary gland: progressive acquisition of smooth muscle phenotype, Dev. Dyn. 204 (1995) 107-117.

[50] L.A. Sabourin, M.A. Rudnicki, The molecular regulation of myogenesis, Clin. Genet. 57 (2000) 16-25.

[51] N. Nukumi, K. Ikeda, M. Osawa, T. Iwamori, K. Naito, H. Tojo, Regulatory function of whey acidic protein in the proliferation of mouse mammary epithelial cells in vivo and in vitro, Dev. Biol. 274 (2004) 31-44. 


\section{Figure legends}

Fig. 1. The expression of cathepsin E in mouse mammary gland. (A) Quantitative RT-PCR analysis of cathepsin E gene in the mammary gland of wild-type mice. The relative values were defined as the ratio of mRNA level of each tissue to that of brain. The data are the means of three independent experiments. (B) SDS-PAGE and immunoblot analysis of the cell extract of mouse mammary gland compared with purified rat spleen cathepsin $\mathrm{E}$ using antibodies specific to rat cathepsin E. (C) SDS-PAGE and immunoblot analysis of the cell extract of mouse mammary gland with or without acid treatment at $\mathrm{pH} 3.5$ and $37^{\circ} \mathrm{C}$ for $10 \mathrm{~min}$.

Fig. 2. Carmine Alum stained sections of whole-mount preparations of mammary gland from multiparous and non-pregnant wild-type (the upper panel) and $\mathrm{CatE}^{-/}$(the lower panel) mice at 11 months of age. The ducts of $\mathrm{CatE}^{-/-}$mammary gland were more profoundly enlarged than those of the normal gland, in which a lot of hyperplastic alveolar nodules were observed. Scale bar: $1 \mathrm{~mm}$. 
Table 1

Genes upregulated ( $>5$-fold) in the mammary gland of $\mathrm{CatE}^{-/-}$mice $(\mathrm{KO})$ compared with that of the wild-type littermates (WT).

\begin{tabular}{|c|c|c|}
\hline GenBank & $\mathrm{KO} / \mathrm{WT}$ & Gene \\
\hline BC003207 & 80.33 & Mus musculus cDNA clone IMAGE:3587523, partial cds. \\
\hline BE686792 & 63.81 & DNA segment, Chr 14, Wayne State University 89, expressed \\
\hline NM_011709 & 32.60 & whey acidic protein \\
\hline AV376376 & 24.19 & Transcribed sequences \\
\hline NM_133892 & 22.31 & L-amino acid oxidase 1 \\
\hline NM_013626 & 16.54 & peptidylglycine alpha-amidating monooxygenase \\
\hline NM_011315 & 13.45 & serum amyloid A 3 \\
\hline AF128193 & 13.18 & chemokine (C-C motif) ligand 7 \\
\hline BC021368 & 12.23 & transmembrane protease, serine 4 \\
\hline NM_008108 & 11.85 & growth differentiation factor 3 \\
\hline BB246912 & 11.49 & RIKEN cDNA 1700112E06 gene \\
\hline NM_010679 & 10.62 & lactalbumin, alpha \\
\hline BC003705 & 10.34 & surfactant associated protein $\mathrm{D}$ \\
\hline BB276544 & 10.01 & $\begin{array}{l}\text { BB276544 RIKEN full-length enriched, } 10 \text { days neonate cortex Mus } \\
\text { musculus cDNA clone A830097P08 3', mRNA sequence. }\end{array}$ \\
\hline BB200905 & 9.96 & $\begin{array}{l}\text { BB200905 RIKEN full-length enriched, } 0 \text { day neonate thymus Mus } \\
\text { musculus cDNA clone A430031J12 3', mRNA sequence. }\end{array}$ \\
\hline NM_009141 & 9.54 & chemokine (C-X-C motif) ligand 5 \\
\hline M11024 & 9.24 & $\begin{array}{l}\text { envelope polyprotein; Mouse endogenous mammary tumor virus } \\
\text { (MMTV) RNA, env gene and right LTR. }\end{array}$ \\
\hline NM_010174 & 8.32 & fatty acid binding protein 3 , muscle and heart \\
\hline BB280937 & 7.16 & $\begin{array}{l}\text { Adult retina cDNA, RIKEN full-length enriched library, clone: } \\
\text { A930028O11 product:unclassifiable, full insert sequence }\end{array}$ \\
\hline NM_009258 & 6.86 & serine protease inhibitor, Kazal type 3 \\
\hline BB143568 & 6.19 & orphan short chain dehydrogenase/reductase \\
\hline AV333665 & 5.75 & RIKEN cDNA 6330549D23 gene \\
\hline BI658627 & 5.68 & secreted frizzled-related sequence protein 1 \\
\hline BB386209 & 5.00 & $\begin{array}{l}\text { BB386209 RIKEN full-length enriched, } 0 \text { day neonate cerebellum } \\
\text { Mus musculus cDNA clone C230045D21 3', mRNA sequence. }\end{array}$ \\
\hline
\end{tabular}


Table 2

Genes down-regulated (>6-fold) in the mammary gland of $\mathrm{CatE}^{-/-}$mice $(\mathrm{KO})$ compared with that of the wild-type littermates (WT).

\begin{tabular}{|c|c|c|}
\hline GenBank & $\mathrm{KO} / \mathrm{WT}$ & Gene \\
\hline AI595938 & 0.0363 & RIKEN cDNA 6530403D07 gene \\
\hline BM122177 & 0.0748 & RIKEN cDNA 2310036G12 gene \\
\hline AV005759 & 0.0749 & $\begin{array}{l}\text { Mus musculus C57BL/6J heart Mus musculus cDNA clone } \\
\text { 1010001P05, mRNA sequence. }\end{array}$ \\
\hline BC008538 & 0.0771 & myosin, heavy polypeptide 2, skeletal muscle, adult \\
\hline AI326984 & 0.0773 & RIKEN cDNA 1110007C05 gene \\
\hline AK009042 & 0.0784 & creatine kinase, mitochondrial 2 \\
\hline ВC025840 & 0.0801 & titin \\
\hline AV007148 & 0.0827 & troponin I, skeletal, fast 2 \\
\hline AJ002522 & 0.0833 & myosin, heavy polypeptide 1 , skeletal muscle, adult \\
\hline NM_021484 & 0.0843 & titin immunoglobulin domain protein (myotilin) \\
\hline NM_009813 & 0.0897 & calsequestrin 1 \\
\hline AW108242 & 0.0946 & RIKEN cDNA 8030451F13 gene \\
\hline NM_007933 & 0.0981 & enolase 3 , beta muscle \\
\hline NM_022314 & 0.0986 & tropomyosin 3, gamma \\
\hline AF223417 & 0.0995 & triadin \\
\hline NM_013456 & 0.101 & actinin alpha 3 \\
\hline NM_016712 & 0.104 & tropomodulin 4 \\
\hline BG794681 & 0.108 & cDNA clone IMAGE:3488793 \\
\hline NM_010861 & 0.111 & myosin, light polypeptide 2, regulatory, cardiac, slow \\
\hline NM_029569 & 0.111 & ankyrin repeat and SOCs box-containing protein 5 \\
\hline NM_011620 & 0.112 & troponin T3, skeletal, fast \\
\hline AK003186 & 0.113 & tropomyosin 2, beta \\
\hline NM_021508 & 0.114 & myozenin 1 \\
\hline BG793713 & 0.115 & ryanodine receptor 1 , skeletal muscle \\
\hline NM_011224 & 0.117 & muscle glycogen phosphorylase \\
\hline NM_013808 & 0.120 & cysteine and glycine-rich protein 3 \\
\hline AF422244 & 0.124 & RIKEN cDNA 2310001N14 gene \\
\hline AI462244 & 0.124 & c6.1a protein \\
\hline
\end{tabular}


(continued)
AJ278733
0.127 myosin heavy chain IIB
NM_007504 0.132 ATPase, $\mathrm{Ca}++$ transporting, fast twitch 1
AK010167 $0.132 \quad$ titin-cap
NM_025357 $0.134 \quad$ small muscle protein, X-linked
NM_010243 0.134 fucosyltransferase 9
D61689 $\quad 0.137 \quad$ SRY-box containing gene 6
NM_011079 0.138 phosphorylase kinase gamma
NM_008733 0.144 nebulin-related anchoring protein isoform S; nebulin-related anchoring protein isoform $\mathrm{C}$
NM_010473 $0.146 \quad$ histidine rich calcium binding protein
AK003186 0.153 tropomyosin 2, beta
BC025172 0.154 myoglobin
BQ031098 $\quad 0.160 \quad$ WD repeat and FYVE domain containing 1 
Table 3

Classification of genes identified as overexpressed ( $>2$-fold) in the mammary gland of $\mathrm{CatE}^{-/-}$mice (KO) compared with that of the wild-type littermates (WT).

\begin{tabular}{|c|c|}
\hline NM_080843 & suppressor of cytokine signalling 4 \\
\hline NM_013654 & chemokine (C-C motif) ligand 7 \\
\hline NM_009141 & chemokine (C-X-C motif) ligand 5 \\
\hline NM_020572 & aurora kinase $\mathrm{C}$ \\
\hline NM_030614 & fibroblast growth factor 16 \\
\hline NM_009140 & chemokine (C-X-C motif) ligand 2 \\
\hline NM_009843 & cytotoxic T-lymphocyte-associated protein 4 \\
\hline NM_009425 & tumor necrosis factor (ligand) superfamily, member 10 \\
\hline NM_011347 & selectin, platelet \\
\hline NM_008176 & chemokine (C-X-C motif) ligand 1 \\
\hline NM_011067 & period homolog 3 \\
\hline NM_008510 & chemokine ( $\mathrm{C}$ motif) ligand 1 \\
\hline NM_008998 & RAB17, member RAS oncogene family \\
\hline NM_133212 & toll-like receptor 8 \\
\hline NM_008199 & histocompatibility 2, blastocyst \\
\hline NM_011331 & chemokine (C-C motif) ligand 12 \\
\hline NM_010846 & myxovirus (influenza virus) resistance 1 \\
\hline NM_007843 & defensin beta 1 \\
\hline NM_145227 & 2'-5' oligoadenylate synthetase 2 \\
\hline NM_021274 & chemokine (C-X-C motif) ligand 10 \\
\hline NM_023124 & histocompatibility 2, Q region locus 8 \\
\hline NM_126166 & toll-like receptor 3 \\
\hline NM_016719 & growth factor receptor bound protein 14 \\
\hline NM_008331 & interferon-induced protein with tetratricopeptide repeats 1 \\
\hline NM_008332 & interferon-induced protein with tetratricopeptide repeats 2 \\
\hline NM_010501 & interferon-induced protein with tetratricopeptide repeats 3 \\
\hline NM_011852 & 2'-5' oligoadenylate synthetase $1 \mathrm{G}$ \\
\hline NM_008493 & leptin \\
\hline
\end{tabular}


(continued)

growth factor activity

NM_053087 epithelial mitogen

NM_008108 growth differentiation factor 3

NM_013611 nodal

NM_018865 WNT1 inducible signaling pathway protein 1

NM_008342 insulin-like growth factor binding protein 2

NM_009704 amphiregulin preproprotein

NM_022024 glia maturation factor, gamma

\begin{tabular}{ll}
\hline Cell cycle & \\
\hline NM_010848 & myeloblastosis proto-oncogene product \\
NM_011249 & retinoblastoma-like protein 1 (cell cycle-negative) \\
NM_007891 & E2F transcription factor 1 \\
NM_011193 & proline-serine-threonine phosphatase-interacting protein 1 (cytokinesis) \\
NM_010514 & insulin-like growth factor 2 \\
NM_010756 & v-maf musculoaponeurotic fibrosarcoma oncogene family, protein G \\
\hline
\end{tabular}


Table 4

Classification of genes identified as underexpressed ( $>2$-fold) in in the mammary gland of $\mathrm{CatE}^{-/-}$mice (KO) compared with that of the wild-type littermates (WT).

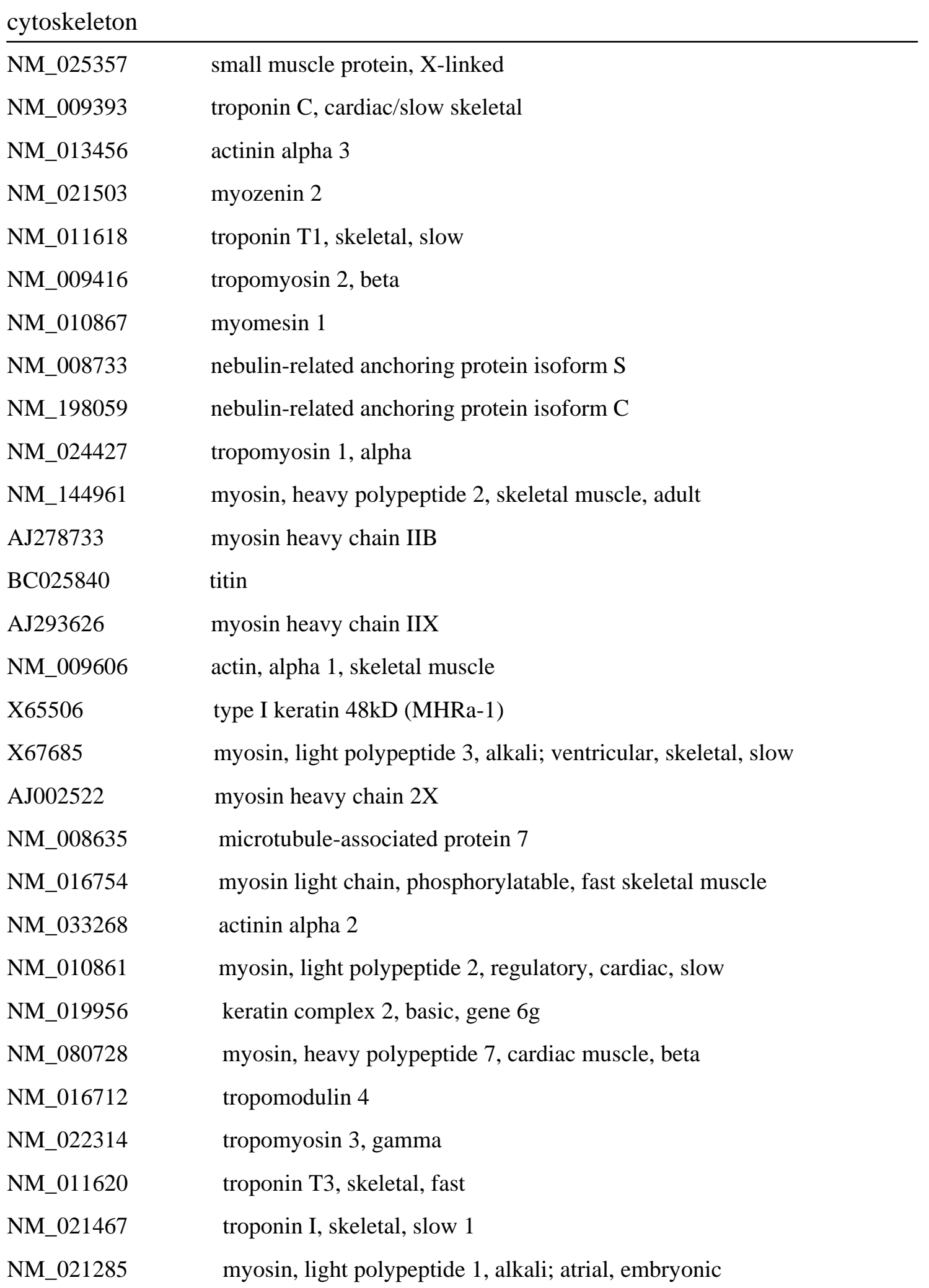


(continued)

$\begin{array}{ll}\text { NM_021508 } & \text { myozenin } 1 \\ \text { NM_021447 } & \text { ring finger protein } 30\end{array}$

cell differentiation

$\begin{array}{ll}\text { AF100171 } & \text { myeloid leukemia factor 1 } \\ \text { NM_008657 } & \text { myogenic factor 6 } \\ \text { NM_011098 } & \text { paired-like homeodomain transcription factor 2 } \\ \text { NM_011445 } & \text { SRY-box containing gene 6 } \\ \text { NM_009379 } & \text { thrombopoietin }\end{array}$

immune response

NM_008324 indoleamine-pyrrole 2,3 dioxygenase

NM_145581 Sialic acid binding Ig-like lectin 5

NM_010391 histocompatibility 2, Q region locus 10

NM_009913 chemokine (C-C motif) receptor 9

cell cycle arrest, anti-apoptosis

\begin{tabular}{ll}
\hline NM_021515 & adenylate kinase 1 \\
NM_021284 & c-K-ras2 protein \\
NM_146066 & G1 to phase transition 1 \\
NM_011641 & transcription factor \\
NM_007906 & eukaryotic translation elongation factor 1 alpha 2
\end{tabular}

Signal Transduction

NM_010600 potassium voltage-gated channel, subfamily $\mathrm{H}$, member 1

NM_010207 fibroblast growth factor receptor 2 isoform IIIc

NM_023635 RAB27A protein

NM_016868 hypoxia inducible factor 3, alpha subunit

NM_011268 regulator of G-protein signaling 9

NM_010276 GTP binding protein (gene overexpressed in skeletal muscle)

NM_133485 PKC-potentiated PP1 inhibitory protein

NM_021411 RAB37, member of RAS oncogene family 
(A)

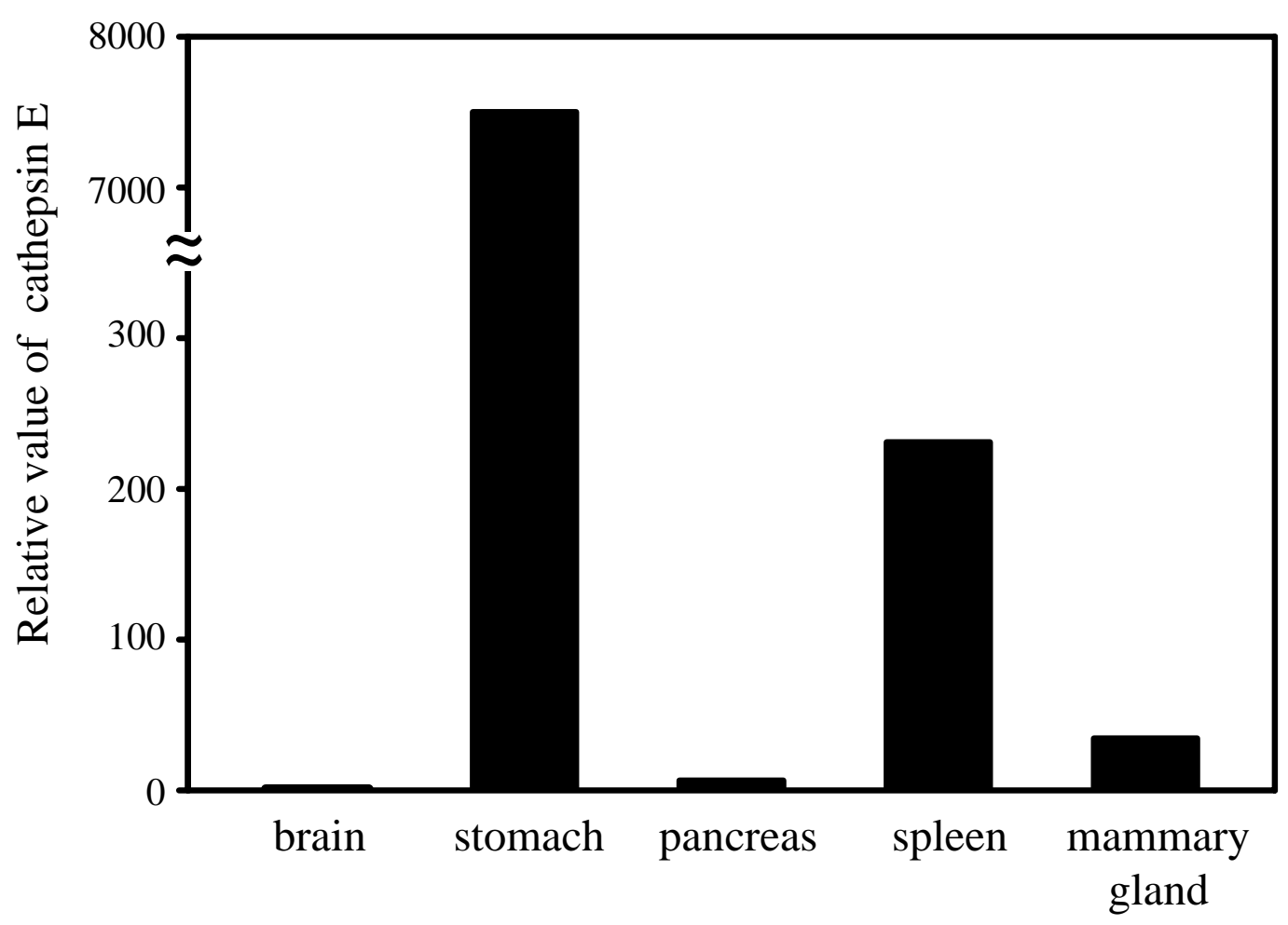

(B)

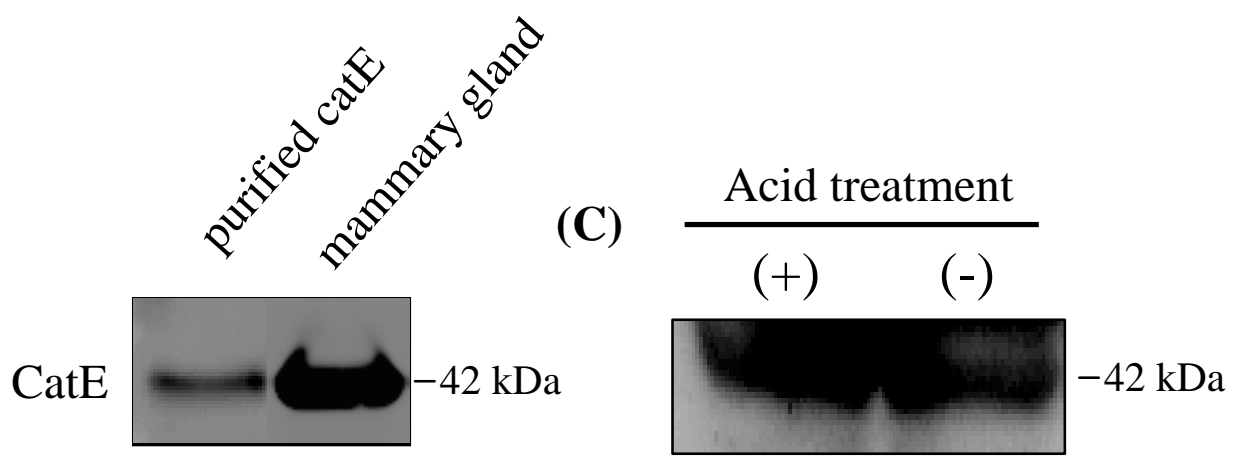

Fig. 1 Kawakubo et al. 

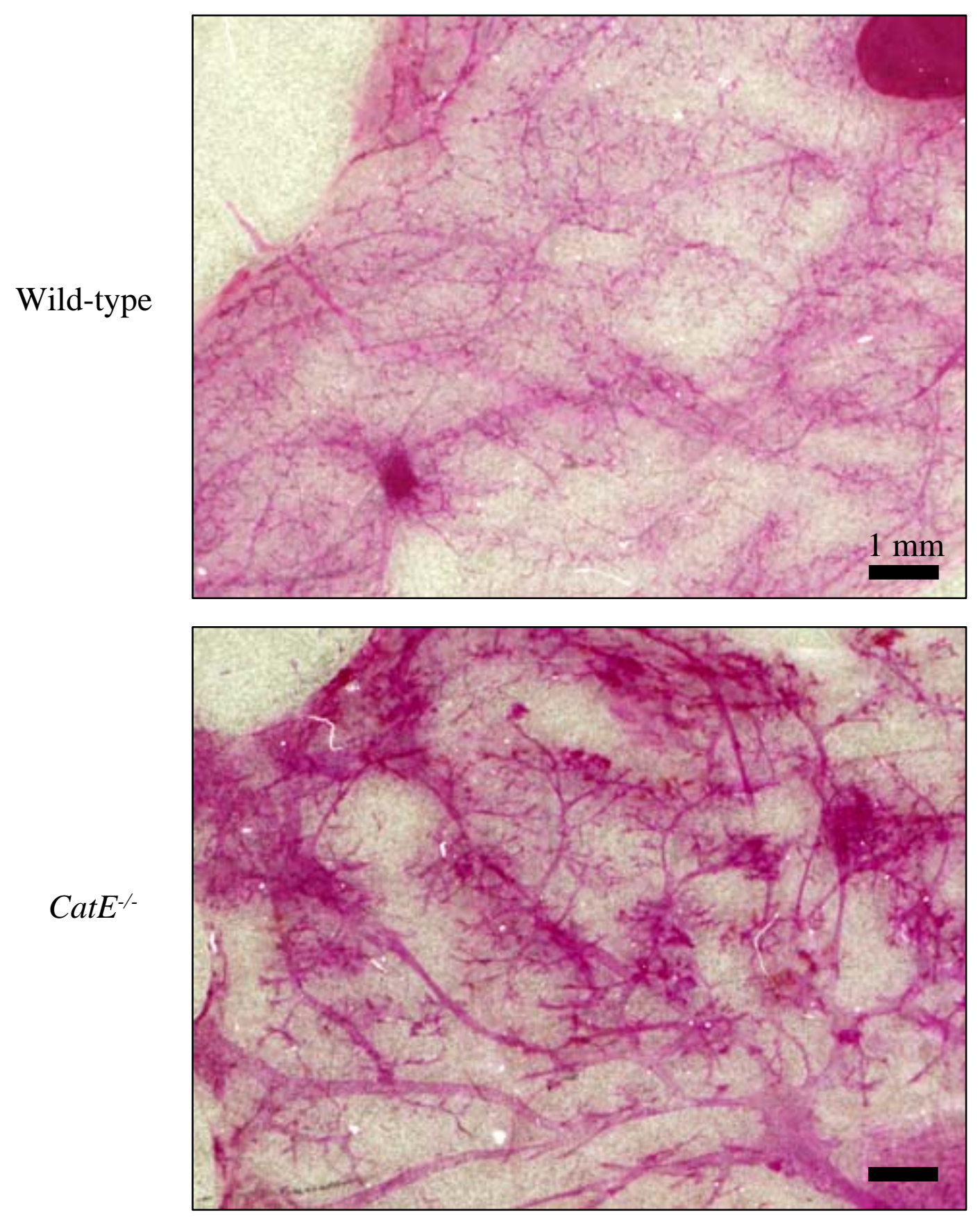

Fig. 2 Kawakubo et al. 